\title{
Jacques-Auguste de Thou, La vie de Jacques-Auguste de Thou (I. Aug. Thuani vita)
}

\section{Michele Mastroianni}

\section{(2) OpenEdition}

\section{Journals}

\section{Edizione digitale}

URL: http://journals.openedition.org/studifrancesi/9482

DOI: $10.4000 /$ studifrancesi.9482

ISSN: 2421-5856

\section{Editore}

Rosenberg \& Sellier

\section{Edizione cartacea}

Data di pubblicazione: 1 décembre 2007

Paginazione: 642

ISSN: 0039-2944

\section{Notizia bibliografica digitale}

Michele Mastroianni, «Jacques-Auguste de Thou, La vie de Jacques-Auguste de Thou (I. Aug. Thuani vita)», Studi Francesi [Online], 153 (LI | III) | 2007, online dal 30 novembre 2015, consultato il 12 janvier 2021. URL: http://journals.openedition.org/studifrancesi/9482 ; DOI: https://doi.org/10.4000/

studifrancesi.9482

Questo documento è stato generato automaticamente il 12 janvier 2021.

\section{(c) $(1)(8)$}

Studi Francesi è distribuita con Licenza Creative Commons Attribuzione - Non commerciale - Non opere derivate 4.0 Internazionale. 


\title{
Jacques-Auguste de Thou, La vie de Jacques-Auguste de Thou (I. Aug. Thuani vita)
}

\author{
Michele Mastroianni
}

\section{NOTIZIA}

JACQUES-AUGUSTE DE THOU, La vie de Jacques-Auguste de Thou (I. Aug. Thuani vita), introduction, établissement du texte, traduction et notes par Anne TEISSIER-ENSMINGER, Paris, Champion, 2007 («Textes de la Renaissance», 126), pp. 1085.

1 La Vita dell'umanista Jacques-Auguste de Thou, che copre gli anni 1553-1601, è un documento di primaria importanza per studiare un periodo intricatissimo della storia (religiosa, politica, culturale e sociale) di Francia. Autobiografia di un intellettuale, ricostruisce incontri e rapporti a livello di ambienti colti e di studio, descrivendo luoghi (si pensi alle pagine del primo libro consacrate al viaggio in Italia) e istituzioni culturali. Tutti i resoconti dei numerosi viaggi (alle pp. 1035-1040 abbiamo un riepilogo degli itinerari percorsi da de Thou) sono interessanti come testimonianza di costumi e attestato di erudizione antiquaria. Importanti, in particolare, sono i riferimenti alla vita politica sotto gli ultimi Valois, attraverso il racconto dei numerosi incontri con i grandi della vita politica. L'insieme offre, poi, una vera e propria storia delle guerre di religione. L'importanza di questa pubblicazione è anzitutto d'ordine filologico, in quanto per la prima volta possiamo usufruire di un'edizione basata sull'autografo, collazionato con tutti i manoscritti che hanno tradito il testo e con l'editto princeps del 1621. La ricchissima Introduzione (pp. 9-184) è anzitutto una ricostruzione e uno studio delle varie fasi della composizione del testo, delle sue stratificazioni, dei problemi che pone la tradizione manoscritta. Ed è anche un'indagine volta a ricostruire La mémoire en procès de l'historien de Thou (pp. 121-184), mettendo in evidenza il lavoro di riflessione giuridica e, più genericamente, ideologica sottostante quelli che A. Teissier-Ensminger 
definisce les rouages d'une jurisécriture. Le annotazioni puntuali e gli indici concorrono a fare di questa edizione un utile strumento di consultazione e di lavoro. 